Revista de la red interuniversitaria de estudios sobre las literaturas rioplatenses contemporáneas en Francia

$6 \mid 2011$

Juan José Saer. archivos, memoria, critica

\title{
La Grande: volver a empezar
}

Julio Premat

\section{OpenEdition}

Journals

Edición electrónica

URL: http://journals.openedition.org/lirico/239

DOI: $10.4000 /$ lirico. 239

ISSN: 2262-8339

Editor

Réseau interuniversitaire d'étude des littératures contemporaines du Río de la Plata

Edición impresa

Fecha de publicación: 1 diciembre 2011

Paginación: 173-182

ISBN: 2-9525448-5-9

ISSN: 2263-2158

\section{Referencia electrónica}

Julio Premat, «La Grande: volver a empezar », Cuadernos LIRICO [En línea], 6 | 2011, Puesto en línea el

01 julio 2012, consultado el 01 mayo 2019. URL : http://journals.openedition.org/lirico/239 ; DOI :

10.4000/lirico.239

\section{(c) ${ }_{\mathrm{EY}}(\mathrm{NQ} \mathrm{ND}$}

Cuadernos LIRICO está distribuido bajo una Licencia Creative Commons Atribución-NoComercial-

SinDerivar 4.0 Internacional. 


\title{
LA GRANDE: VOLVER A EMPEZAR
}

\author{
Julio Premat \\ Université Paris 8 - LER
}

\section{Comienzo. Primera cita}

T alga la tautología: para comenzar, lo más simple es el comienzo, la primera frase del primer borrador de La grande, fechado en julio del 95. El primer incipit previsto para todo el libro, corregido varias veces en un cuaderno y desechado luego era: "Y por suerte volvió, con el otoño, el tiempo del vino". Incipit instalado en una continuación ("Y"), que habría anunciado, si hubiese sido el incipit definitivo, la idea de una vuelta -de un retorno-, de una vuelta bienhechora ("por suerte") pero también la de un comienzo: el del otoño, el de un tiempo distinto, el tiempo del vino. En documentos prerredaccionales posteriores, la frase reaparece un sinnúmero de veces, cada vez reescrita y transformada, como un tema que se repite y varía a lo largo de la emergencia de la novela. Por ejemplo esta serie, en una hoja suelta, en la que leemos:

Llegó el otoño, el tiempo del vino.

Con el otoño, llegó el tiempo del vino.

Llegó, con el otoño, el tiempo del vino.

De modo que llegó, con el otoño, el tiempo del vino.

Y por suerte volvió, con el otoño, el tiempo del vino.

Así que llegó, con el otoño, el tiempo del vino. ${ }^{1}$

Esa llegada y ese cambio (ese comienzo) parecen acompañar la escritura de todo el texto: repetición y novedad, tema y variaciones. Finalmente, Saer decide posponer la inclusión de la frase, aparentemente central en el proceso productivo, hasta el incipit de la última parte. Y como ustedes saben es en esa primera frase del último capítulo del libro que concluye el manuscrito de La grande: "Con la lluvia, llegó

\footnotetext{
${ }^{1}$ Esta cita, como otras que figuran más lejos, está sacada del material inédito dejado por el escritor, y que ha sido catalogado y transcrito en el marco del proyecto Fonds Saer. Archives, mémoire, critique.
} 
el otoño, y con el otoño, el tiempo del vino." "2 La novela, y toda la obra de Saer, termina con una frase inaugural, con un título ("Lunes. Río abajo"), con el anuncio de un comienzo (el del otoño, el de un tiempo diferente, el del vino, que parece compensar la llegada de la lluvia). La vuelta es menos visible y menos positiva que en el primer borrador incipit (recuérdese: «Y por suerte volvió, con el otoño, el tiempo del vino»); lo que se pone de relieve ahora es una llegada (acorde con el día "Lunes" que comienza una nueva semana), una inminencia del frío y del vino, un movimiento río abajo hacia la desembocadura, hacia el final de la novela, ese excipit inminente. La novela, la obra de Saer, se cierra así con un final trunco que habla de varios comienzos y que retoma la primera frase escrita del primer borrador. La grande también termina con esa página en blanco, la del otoño, la de la muerte, la de la última palabra no escrita. La última frase de la obra de Saer es, desde varios puntos de vista, la primera. El fin mira al principio, el después está en la perspectiva de una anterioridad, el desenlace nos habla del comienzo y del origen. Un dispositivo que pone en escena así dos tiempos simultáneos, estructura, puede pensarse, toda la novela.

\section{Retorno. Segunda cita}

En el tercer capítulo, “Jueves. De crecida”, dos personajes tienen una visión, una fenomenal epifanía, quizás la más fuerte de la obra de Saer. Son personajes de la "tercera generación”, es decir jóvenes. Gabriela, hija de Barco, que está embarazada y Soldi, los "historiadores" de la vida literaria de la ciudad, están sentados en una playa, mirando las ruinas del puente colgante, destruido unos diez años antes, ruinas que se terminan, bruscas, en un vacío. Y de pronto «ven» en ese puente a dos muchachos:

Parecen haber descubierto al mismo tiempo a los dos muchachos jóvenes, mucho más jóvenes que ellos, que, seguramente debido a una larga caminata, se han apoyado sudorosos contra la barandilla de metal para descansar un rato gozando de la frescura del río, antes de volver a sus casas, darse una ducha rápida y volver a salir a las promesas y a los ritos de la noche.

2 Edición estudiada: Juan José Saer, La grande, Buenos Aires, Seix-Barral, 2005. Los números de página entre paréntesis remiten a esta edición. Sobre el carácter póstumo de la novela, consultar: Jorge Monteleone, "Lo póstumo: Juan José Saer y La grande", Insula $\mathrm{n}^{\circ}$ 711, Madrid, marzo 2006, pp. 14-17. 
No tienen dificultades en reconocerlos, a pesar de la distancia: son Tomatis y Barco. Y a pesar de ella, oyen inclusive un diálogo:

De pronto uno de ellos, el más alto, el más calmo, el más paciente, sin aviso pero sin brusquedad, pregunta: ¿Qué es la novela? Y el otro, un poco más joven, sin siquiera levantar la vista del torbellino: El movimiento continuo descompuesto. (p. 199-200).

La definición de la novela como un "movimiento continuo descompuesto" es un aforismo que Saer escribe en un cuaderno de notas a principios de los sesenta, aforismo que retoma en los papeles preparatorios de Glosa en los ochenta y que recupera para La grande. En la novela se lo cita dos veces: la anécdota es narrada primero irónicamente, y luego asociada con la visión del puente colgante enriqueciendo su sentido, ya que el aforismo está ahora puesto en relación con el flujo temporal metaforizado por el torbellino de las aguas del río. Por otro lado, con los desplazamientos del caso (el diálogo tiene lugar en el momento del crepúsculo y no en la madrugada), podríamos leer esta escena como una variante de la escena final de "Algo se aproxima", cuando Barco y Tomatis pasan "casi media hora sobre la plataforma del puente colgante". Recuérdese que a la hora de organizar todos sus cuentos en un volumen único (los Cuentos completos publicados en el 2001), Saer elige invertir el orden de publicación, situando por lo tanto el comienzo al final (En la zona es el último volumen del libro), lo que hace que "Algo se aproxima" y la escena a la que aludo sean, también, en una extraña resonancia con el lugar que ocupa La grande en la bibliografía del autor, en alguna medida la última escena del último cuento.

O sea que aquí también la novela postrera mira hacia atrás, mira hacia el comienzo, hacia el final de ese comienzo (las últimas peripecias del último relato de En la zona), hacia lo que fue (la juventud de Barco y Tomatis), hacia eso que ya no está (el puente colgante en Santa Fe fue destruido por una inundación en 1983), hacia eso que la fundó y que de pronto se materializa, así como la hija, embarazada, es decir en gestación de un posible personaje futuro de la obra de Saer, mira la juventud de su padre, más joven de lo que ella es en ese momento. Se produce una imagen (la visión del puente colgante) con la memoria, una memoria que es la de la obra y no la de los personajes. Se produce una imagen mezclando recuerdo y percepción, se percibe una imagen 
con otra - una anterior, otra simultánea- y por lo tanto se percibe lo que existe con lo inexistente. ${ }^{3}$

Esta imagen sintetiza la idea del retorno, ampliando su sentido argumental en varias direcciones: vuelta a y vuelta de la obra anterior de Saer, retorno al pasado, dinámica del recordar. Digamos que el retorno configura y determina una serie de operaciones de la novela que son en buena medida ajenas a las intrigas y al desenlace. En el centro -o en la superficie-: retorno de Gutiérrez que, después de treinta años, regresa por primera vez. Su regreso, nunca explicado del todo, es en buena medida un fracaso, como era de preverse: la repetición es imposible, el pasado está fuera de alcance y la ciudad no corresponde con la de sus recuerdos. O sea que la obra, después de narrar numerosas partidas de la zona y destierros consecuentes, narra, en su última peripecia, un intento de retorno definitivo (es una verdadera vuelta, fracasada, enigmática, pero vuelta al fin y al cabo), que se refleja y repite en varios personajes (Nula vuelve de Paraná, Tomatis de Rosario). Por otro lado, una serie tenue de referencias a Ulises, en tanto que emblema del regreso "a casa" después de un largo viaje, pero también, más ampliamente, a los nostos, serie de textos perdidos que narran los regresos de la Guerra de Troya (p. 94), abren la perspectiva de esta anécdota de Gutiérrez a una esfera no sólo intertextual sino legendaria.

Sea como fuere, este retorno lleva a la yuxtaposición de dos tiempos (el de la actualidad, el del pasado de los personajes) y de dos planos textuales: lo que leemos y los relatos precedentes, convocados y citados a cada paso. El retorno de Gutiérrez es, entonces, el punto de partida de una posición de revisión, reminiscencia, recuperación y reescritura de la obra anterior. La posición de Gabriela y Soldi que son, repito, jóvenes e historiadores de la literatura, es la del propio escritor ante sus textos ya escritos, textos citados y prolongados en mil direcciones diferentes en la novela. Volver es volver a la obra e iniciar una nueva vuelta, una inédita vuelta completa a partir de los mismos elementos. La repetición nunca es perfecta-Barco y Tomatis están sobre el puente a la tarde, no a la madrugada-; pero el hecho de rememorar y retomar

${ }^{3}$ Como lo afirma Sibony: "On sait bien que la production de l'image concerne mémoire et perception. Mais elle concerne aussi la perception différenciée de la mémoire. On perçoit une image avec une autre -antérieure ou simultanée- donc avec sa mémoire, celle du passé et de l'avenir-vision ou prévision, retard ou anticipation-. Donc on produit aussi l'image avec sa mémoire." (Daniel Sibony, Entre-deux. L'origine en partage, Paris, Seuil, 1991, p. 265). 
lo mismo es una manera, típicamente saeriana, de introducir lo nuevo. La escena exhibe un procedimiento de escritura: la repetición y su desplazamiento hacia una representación imperfecta de lo anterior es un segundo principio de construcción de La grande.

En ese sentido, constatamos que la mirada retrospectiva es también hacia el proceso en sí de escritura, hacia el trabajo de anotación y preparación de lo publicado. Porque en el episodio citado aparece esa afirmación digamos metaficcional, la definición de la novela como un movimiento continuo descompuesto que parece jugar el papel de una definición poética de la novela que leemos. Abriendo esta perspectiva, fértil pero previsible, digamos que esa cita no sólo funciona como un gesto autorreflexivo. La frase citada convoca, en la parte pública y legible de la obra, su parte oculta, los cuadernos, y los procesos de escritura, lectura, relectura, reescritura, que los caracterizan: se expone, no sólo una frase escrita a mediados de los sesenta, sino el gesto de producción que supone una escritura a partir de la relectura del material genético de otros textos. Nótese, por otro lado, que la frase no es el único ejemplo de una escritura en dos tiempos: toda la historia del precisionismo, incluida a comienzos del "Sábado" y que Tomatis lee en el autobús que lo lleva de vuelta a la ciudad, es un texto escrito antes, quizás en los 80 , única huella visible del proyecto de El intrigante que se introduce en el flujo de una escritura posterior.

Podemos, entonces, constatar un cambio en la recuperación e inclusión de las notas prerredaccionales. En un cuaderno de principios de los sesenta leemos:

No permitiré que nadie penetre en mis cuadernos, como han hecho con Kafka, o con Pavese. No me moriré. Yo elegiré con el tiempo cuál es la palabra justa y necesaria que debo decir, y el resto lo echaré al fuego. Sé que tengo madera de escritor de los grandes, y mi deber consiste en no permitir que celebren como verdades mis equivocaciones, o como genialidades mis torpezas.

En negativo, esta cita afirma una conciencia sobre la importancia de los cuadernos en lo que se ha dado en llamar el "taller" del escritor. Aunque la posición ante ellos vaya cambiando, Saer siempre guardó cuidadosa -y caóticamente- sus papeles, como una versión paralela y secreta de los libros publicados (papeles que tenían su lógica de organización, circuitos propios de lectura y funciones complejas en el proceso de escritura). En este sentido, leer La grande a partir de los cuadernos pone de relieve a un «precursor velado» pero a mi modo de 
ver fundamental, que es Flaubert (relación que merecería un estudio específico): o al menos, una identificación heroica con él. Admitido esto, no es sorprendente que Tomatis cite la Correspondencia de Flaubert en La grande y que en la biblioteca de Saer haya figurado una edición, cuidadosamente leída, de los Carnets del mismo escritor.

Retomando el fragmento comentado. Frente al anatema de los sesenta, anatema que implicaba una ocultación de los titubeos propios del proceso creativo, ahora, con la inclusión de una frase de esos mismos años sesenta, no sólo se vuelve argumental y temáticamente a muchos textos ya publicados, sino que también se le da cabida, en lo que leemos, a la dimensión genética, a esos cuadernos y notas. Inclusive, después de tantas y tan variadas puestas en escena de la escritura de las novelas, en La grande asistimos a una ficción de escritura, no de relatos, sino de los cuadernos de notas y carnets de viaje que llevaba Saer: Nula vive experiencias, tiene recuerdos y asociaciones, y toma cuidadosas notas en una libretita, siguiendo inclusive el tipo de sintaxis y de organización formal que caracteriza los cuadernos del escritor. Por ejemplo, en medio de una conversación con Soldi y Gabriela, Nula anota ideas surgidas de experiencias sensoriales:

[Nula] mete la mano en el bolsillo interior del saco y extrayendo la libretita de hule negro, la abre; debajo de la última anotación que escribió ayer en Paraná, casi a la misma hora, al salir de lo de Lucía -El caos percibido como armonía por deficiencia sensorial. Vuelo de mariposas-, dejando un renglón y trazando una raya horizontal breve en medio del renglón para separarla de la anotación siguiente, bajo la mirada intrigada pero discreta de Gabriela y Soldi, después de meditar unos segundos como si hubiese estado solo, apoya la libreta sobre la barra transversal del volante y sin apurarse para nada escribe: Ilusión óptica y realidad exterior (Horizonte, paralelas, etc.). (pp. 181-182)

Esta anécdota, dicho sea de paso, nos propone claves de lectura y de interpretación de las innumerables frases enigmáticas que circulan en los cuadernos y libretas de Saer (aunque, por supuesto, el tipo de experiencia y de reflexión propuestas en estos ejemplos vuelva totalmente inútil, de antemano, todo intento de interpretación unívoca).

No es quizás casual que esta inclusión sea simultánea de la decisión de Saer de abrir su "taller" para la preparación de una edición genética de Glosa y de El entenado, y por lo tanto, de la integración, dentro del juego de espejeos, repeticiones y amplificaciones de lo mismo que caracteriza su obra, la inclusión, decía, de otras versiones, la versión prerredaccional, los borradores, los esquemas y anotaciones que 
permitieron la escritura. ${ }^{4}$ Un material que podría leerse, entonces, no como la revelación pública de un secreto, sino como un avatar más de un modo de producción. En todo caso, en términos de origen y de comienzos, la obra integra, en La grande y en la autorización para llevar a cabo la edición Archivos, otra dimensión inaugural, otros principios, otros gestos de emergencia. Como siempre, cada segmento nuevo de la obra, naturaliza, integra, ficcionaliza, las desviaciones anteriores; la publicación, prevista al mismo tiempo que La grande, de la edición Archivos, debía acompañarse, por lo tanto, con versiones imaginarias e inclusiones múltiples del "secreto" allí revelado.

\section{Recuerdo. Tercera cita}

Vuelta a la ciudad, vuelta al pasado, vuelta a lo ya publicado, vuelta al proceso de escritura. Y también: La grande es la novela en que la vuelta fracasa, las acciones proliferan y se vacían, pero algo fundamental sucede. Lo que sucede, como modalidad del gesto de repetición, o sea una recuperación gracias a la representación fugaz, es, por supuesto, el recuerdo, la capacidad de recordar. El regreso de Gutiérrez instaura un movimiento digamos estructural que lleva, a muchos personajes, a una posición de reminiscencia, lo que supone, aquí también, una confrontación de dos tiempos, el ahora y el otrora, en muchos niveles distintos, en una novela retrospectiva que mira hacia el comienzo, al origen, y por lo tanto lo representa, lo crea, con una fuerza inédita. Una novela que vuelve a recordar la dictadura, poniendo en escena, inclusive, episodios de reminiscencia individual y de narración oral al respecto.

Esta constatación me lleva a la tercera cita, un extenso párrafo situado en el inicio del capítulo "Miércoles. La manzana". Se trata de un verdadero catálogo nostálgico de recuerdos que enumera Nula, evocando así su infancia, y que podría considerarse el punto álgido de esta novela que funciona alrededor de una dinámica del regreso de lo pasado. ${ }^{5}$ Cito un fragmento, muy reducido:

4 La edición Archivos de Glosa y El entenado salió en abril de 2010 y contiene una transcripción del material prerredaccional así como una reproducción in extenso de los manuscritos. En sus inicios (es decir, en el 2002), el proyecto era publicarla simultáneamente con La grande. Juan José Saer, Glosa - El entenado, edición crítica y genética coordinada por Julio Premat, Poitiers-Córdoba, Archivos-Alción, 2010.

5 Como siempre en Saer, la novedad tiene antecedentes. Leemos una "protoversión" de esta rememoración en Glosa, cuando Leto viaja al campo durante el fin de semana en el que se suicida su padre. Cf. Juan José Saer, Glosa, Buenos Aires, Seix-Barral, 1995, pp. 82-83. 


\begin{abstract}
Sensaciones táctiles por ejemplo: el contacto caliente y palpitante contra el cuerpo del caballo sudoroso; la frescura súbita, en las tardes de verano, al entrar en algún rincón de sombra del patio inmenso; la tensión resbaladiza de las ranas vivas que trataban de zafar de la mano que las aferraba; [...] O si no olfativas: el olor de los paraísos, de las madreselvas y de los ligustros en flor; el de un excusado que había en el fondo del patio; el de la alfalfa y el de los corrales; el del fuego de leña primero y un rato más tarde el de la carne asándose en la parrilla; [...] O gustativas: el sabor de la bebida hecha con uvas verdes, bien ácidas, que aplastaban en el fondo de una jarra y mezclaban con azúcar, agua y hielo; el de los cigarrillos de chala y barba seca de choclo y más tarde el de los verdaderos cigarrillos y el de las primeras cervezas sacados a escondidas del negocio a la hora de la siesta y que se iban a fumar y a tomar en un baldío que había atrás de la casa [...] Auditivas: el espacio negro de la noche que se descomponía en una multiplicidad de planos diferentes cuando, por una razón cualquiera, los perros del pueblo empezaban a ladrar y a responderse en la oscuridad; el silbato de las locomotoras que pasaban por el pueblo a toda velocidad o el traqueteo de los trenes de carga interminables que, también sin detenerse, lo atravesaban lentos [...] (pp. 83-85)
\end{abstract}

La fuerza, maravilla y plenitud del recuerdo, se perciben, como vemos, no en el relato de circunstancias y peripecias, sino en algo más modesto y más vívido, la recuperación de sensaciones, percepciones, momentos, que hacen revivir el pasado, trasladan al sujeto que recuerda hacia el pasado, ese pasado que cobra, efímeramente, los colores y la fuerza del presente. Y de un pasado fuertemente marcado por la perspectiva autobiográfica en el caso de Nula. En ese sentido es significativo que en el material preparatorio de la novela haya varias fotos personales y postales de Santa Fe, e inclusive que, en algún cuaderno de los manuscritos, en la contratapa, el escritor haya abrochado una foto de un asado con amigos, seguramente de los años 70. Se escribe a partir de las imágenes del recuerdo, o, como lo escribió Nora Catelli, ya no se rememora para escribir, sino que se escribe para rememorar. ${ }^{6}$

Decir que esta capacidad de recordar y narrar el pasado es una novedad en la obra de Saer sería, por supuesto, erróneo. Lo que resulta significativo, creo, es la evidencia que acompaña su emergencia. En ninguna medida se crea un dispositivo que dé lugar a una rememoración como resultado de un proceso problemático (era el caso en Glosa y el

\footnotetext{
${ }^{6}$ Nora Catelli señaló, también, la relación con Proust que desarrollo aquí. $C f$. Nora Catelli, "El presente de la escritura. Sobre La grande de Juan José Saer", Punto de vista $\mathrm{n}^{\circ} 84$, Buenos Aires, abril de 2006, pp. 10-13.
} 
del relato de El entenado, que sólo es posible después de toda una vida y en la frontera con la muerte). Lo nuevo es, entonces, no la focalización en el pasado y en su representación, sino la fuerza inmediata de esa representación, la expansión no problemática de esas sensaciones y percepciones, el vértigo acumulativo de poder reconstruir un mundo y un tiempo, hasta entonces considerado como perdidos.

Es inevitable, en esta perspectiva, ver en el párrafo citado una respuesta o un contrapunto con "La mayor" y con el gesto de Tomatis sopando la galletita en el té, llevándosela a la boca repetidas veces, sin lograr sacar de ella, nada: "ahora que trago, ahora que no queda ni rastro de sabor, sé, decididamente, que no saco nada, pero nada, lo que se dice nada". La experiencia de la magdalena de Proust parecía irrepetible: "Ahora no hay nada, ni rastro, ni recuerdo de sabor: nada". En La grande, el retorno, la posición retrospectiva que parte de Gutiérrez y contamina a todos los personajes y a la construcción misma del texto, lleva a un fluir de la memoria, a un espléndido despliegue del pasado que sí puede compararse con el efecto de la magdalena de Proust. Cito por el gusto nomás de contraponer la prosa de Marcel con la de Saer:

Et dès que j'eus reconnu le goût du morceau de madeleine trempé dans le tilleul que me donnait ma tante (quoique je ne susse pas encore et dusse remettre à bien plus tard de découvrir pourquoi ce souvenir me rendait si heureux), aussitôt la vieille maison grise sur la rue, où était sa chambre, vint comme un décor de théâtre s'appliquer au petit pavillon, donnant sur le jardin, qu'on avait construit pour mes parents sur ses derrières (ce pan tronqué que seul j’avais revu jusque là); et avec la maison, la ville, depuis le matin jusqu'au soir et par tous les temps, la Place où on m'envoyait avant déjeuner, les rues où j'allais faire des courses, les chemins qu'on prenait si le temps était beau. Et comme dans ce jeu où les Japonais s'amusent à tremper dans un bol de porcelaine rempli d'eau, de petits morceaux de papier jusque-là indistincts qui, à peine y sont-ils plongés s'étirent, se contournent, se colorent, se différencient, deviennent des fleurs, des maisons, des personnages consistants et reconnaissables, de même maintenant toutes les fleurs de notre jardin et celles du parc de M. Swann, et les nymphéas de la Vivonne, et les bonnes gens du village et leurs petits logis et l'église et tout Combray et ses environs, tout cela qui prend forme et solidité, est sorti, ville et jardins, de ma tasse de thé.

Para completar la referencia a Proust, seguramente central en $L a$ grande, la escena final, el asado del domingo en el que se reúnen personajes de muchas otras novelas y que retoma, en su intriga misma, comidas de amigos o grupos que recorren toda la obra, funciona como 
un eco o una cita de la célebre matinée en la casa de la duquesa de Guermantes en Le Temps retrouvé, que es, recuérdese, el marco de una serie de revelaciones sobre el recuerdo (y en la cual cabría situar, a su vez, el episodio de la magdalena). Ese episodio de la novela de Proust sería un desenlace de la historia de emergencia de una escritura, pero no el desenlace de una intriga: en los siete apretados tomos de la Recherche nada sucede, nada sucederá, nada más que el cambio de una relación con el recuerdo y la actualización, en esa reunión de personajes envejecidos y envilecidos, de nudos argumentales de toda una impresionante masa textual anterior. En este sentido La grande, novela panorámica y póstuma, sería un desenlace por esta transformación de la relación con el recuerdo, pero también por vaciar al desenlace de toda dimensión argumental o resolutiva: la comida final, como en Proust, en tanto que fin de un comienzo, o que verdadero e imaginario comienzo de una escritura empezada, en los hechos, cuarenta y siete años antes. En el fin, por fin, se puede empezar, empezar de una vez por todas a escribir, delineando la escritura deseada, la escritura del recuerdo. 